\title{
The Effects of Anhedonia in Social Context
}

\author{
Emma Barkus ${ }^{1}$
}

Accepted: 7 July 2021 / Published online: 30 July 2021

(c) The Author(s) 2021

\begin{abstract}
Purpose of Review Anhedonia is a transdiagnostic symptom comprising reduced subjective reward or pleasure. Anhedonia influences subjective anticipation and in-the-moment experiences. This review draws together affective learning and engagement evidence for anhedonia affecting subjective experiences of social environments.

Recent Findings While social engagement is diminished consistently, subjective appraisals of social contexts vary across different mental health disorders. Low positive affect during social experiences or stimuli is reported in PTSD, mood, schizophrenia, and anxiety disorders. Diminished neural reward networks underpin the anticipation of social experiences in ADHD, schizophrenia spectrum, and autistic spectrum disorders. Multiple theories exist to explain how anhedonia might interfere with social environments.

Summary Anhedonia is a barrier to engagement, motivation, and enjoyment of social contexts. While many studies characterize experiences during social contexts, learning theories provide the most promise for developing targeted interventions.
\end{abstract}

Keywords Anhedonia $\cdot$ Social interaction $\cdot$ Social engagement $\cdot$ Positive affect $\cdot$ Motivation

\section{Introduction}

Anhedonia is the reduced capacity to experience positive emotions and pleasure in response to events and activities which usually elicit these feelings. Traditionally, anhedonia is core to mood disorders, characterized as a marked decrease in interest or pleasure from activities [1]. In schizophrenia, anhedonia is subsumed under negative symptoms, although diminished emotional expression and asociality could also indicate anhedonia [1,2]. Anhedonia might also explain the clinical overlap between anxiety and depression [3], although anhedonia contributes to anxiety disorders independently of depression [4]. Increasingly, anhedonia is considered a central symptom in post-traumatic stress disorder (PTSD), where maladaptive coping (such as avoidance) and PTSD symptoms create the conditions for reduced reward and pleasure [5, 6]. Limited research considers anhedonia in people with disordered eating [7], with an emerging literature for understanding social anhedonia, social functioning, and disordered eating $[8,9]$.

Emma Barkus

emma.barkus@norrthumbria.ac.uk

1 Department of Psychology, Northumbria University, Newcastle upon Tyne, UK
There are differences between mental health disorders and self-report measures, according to whether anhedonia is characterized as stable and unremitting (trait), or a symptom of current mental health state (state) (see Table 1). For instance, in depression, PTSD, and anxiety, diagnostic criteria emphasize changes from "normal functioning" [1]. However, anhedonia can indicate illness severity: those with depression who display anhedonia tend to report more severe symptomatology $[10,11]$. Furthermore, both state and trait anhedonia are associated with suicidality $[12 \bullet \bullet, 13 \bullet]$. Anhedonia appears to be, independent of depression, and trait-like in people with anorexia [14]. In patients with schizophrenia, anhedonia has both state and trait elements, trait anhedonia being stable over extended follow-up (i.e., 13 years; [15]) and in ultra-high-risk young people over shorter timeframes (i.e., 1 year; [16]).

Anhedonia shapes subjective experience of day-to-day activities and has deleterious effects on functioning [17]. The social environment surrounding an individual can provide rich support and be beneficial for psychological, emotional, and physical well-being. Individuals denied subjective reward and pleasure from social circumstances are vulnerable to aversive outcomes such as loneliness. A more nuanced understanding of how anhedonia influences the subjective experience of social environments would 


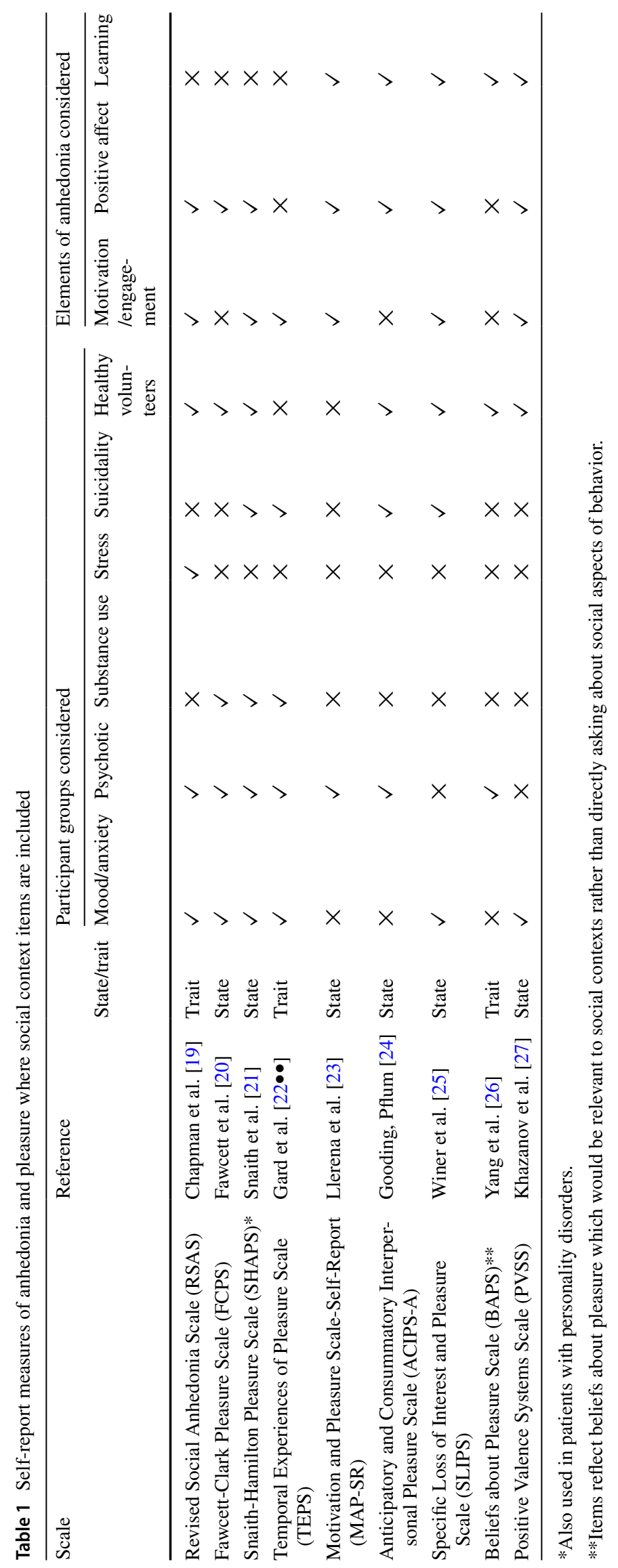


assist development of targeted interventions. The focus of the current review is anhedonia in a social context. Studies will be summarized which consider different elements of anhedonia: motivation and engagement for social interactions, positive affect during social situations, and learning as relevant to social context. Other reviews have considered social anhedonia transdiagnostically [18]; here, the focus concerns the wider construct of anhedonia. References are included for disorders where anhedonia, and its underlying mechanisms, are considered specifically in relation to social context. Therefore, the aim of this narrative review is to draw together research concerning the effects of anhedonia and socially relevant outcomes in mental health disorders.

\section{Anhedonia as Avoidance}

Avoidance of social context is a behavioral consequence of anhedonia. Social networks, social environment, and brain structures are proposed to shape one another during adolescence [28]. In adults, connections to others and social engagement require a balance between cognitive representations of self and others, activating brain areas involved in social cognition representation including the medial prefrontal cortex and cingulate cortex [29]. For instance, when asked to think about a close friend, patterns of activation in the medial prefrontal cortex are reported [30•]. Many studies document avoidance of and withdrawal from social situations, or a preference to be alone in those with mental health disorders. Patients with schizophrenia experience more social isolation [31] and, when with others, report a preference to be alone [32•]. Individuals with depressive symptoms are more likely to feel lonely [33], spend time alone [34], or around individuals with similar levels of depression, or with one other person, rather than a group [35]. Fewer social interactions increase anhedonia and contribute to binge-eating in people with disordered eating [36]. Furthermore, difficulty describing feelings, social anxiety, and social avoidance characterize adolescent females with eating disorders [37].

Alternatively, there may also be preferences for interactions with specific social spheres within someone's networks. For instance, feelings of social safeness are linked to past memories and current attitudes towards eating in those vulnerable to eating disorders [38]. People with social phobia interact more with family members [39] or partners [40] than those outside of their homes. Furthermore, the interactions of those with social anxiety may include fewer personal disclosure, with social anxiety symptoms relating to personal disclosures [41]. Consequently, those with social anxiety disorder have unfulfilled relatedness needs [42]. Consideration of the content of social interactions needs investigating in other mental health disorders. Instances of social withdrawal are reported in most literature concerned with mental health disorders. Positive social support and engagement is seen as part of successful recovery and feelings of social separateness can exacerbate existing symptoms. Avoidance of social situations and more time spent alone could reflect a behavioral outcome from anhedonia; however, less time in social contexts also increases anhedonia. This establishes a spiral of withdrawal and exacerbation which escalates social disconnect. Creating circumstances which sow the seeds of loneliness in emotional conditions that reduce reward could establish conditions for mental health symptoms to become entrenched. While social withdrawal reflects a behavioral outcome from anhedonia, there is a need to understand what drives this need to separate oneself from the social world. To these ends, the rest of this review will consider the mechanisms which potentially underpin social avoidance and withdrawal.

\section{Anhedonia as Low Positive Affect}

Some believe, rather than high negative affect, low positive affect is indicative of anhedonia [43]. Low positive affect in a social context reflects the "liking" or consummatory phase of the pleasure cycle and is underpinned by opioid and GABA receptors [44]. Low positive affect may also be important for in-the-moment experience of social situations in young adults. For instance, socially anxious young adults use alcohol to increase positive affect during social situations [45]. Dysregulated positive affect also plays a role in both extremes of disordered eating, with social interactions contributing to this association [36, 38] Although positive affect does not consistently predict social experiences [46], subjective social competence appears to be associated with positive affect in a reciprocal direction. This means that maintaining high positive affect could be challenging for people with mental health symptoms that compromise social skills, either subjectively or objectively.

\section{What Is the Adolescent Context of Low Positive Affect During Social Contexts?}

Adolescence is a key developmental period for sensitization to social context [47] and represents a vulnerability window where risk trajectories coincide to predict adult psychopathology. There are, unsurprisingly, associations between low positive affect and brain areas underpinning reward in adolescents. In-the-moment experiences of emotional closeness may be most strongly associated with positive affect for adolescents with a reduced (right temporal-parietal junction) neural responsiveness to social reward, while sustained happiness is associated with positive affect in adolescents' sensitivity to social reward [48••]. The right temporalparietal junction may be a converging point for multiple cognitive processes related to social interactions including 
theory of mind and face emotion processing, which could explain its association with social reward responsiveness [49]. Activity in the temporal-parietal junction is also related to social reward value in adults [50], indicating the continued importance of this brain area. Neural responsiveness to social reward might reflect low positive affect during social contexts.

Low positive affect during social contexts is particularly relevant to social anxiety disorder, distinguished from other anxiety disorders by low positive affect [51], particularly in adolescents [52]. The Sensitivity Shift Theory (SST) [53] suggests temperament factors, characterized by increased sensitivity to both positive and negative valence [54], evolve into social anxiety symptoms. Social interactions are highly emotionally laden; consequently, adolescents sensitive to valence engage less socially. Rather than reflecting avoidance, the low social engagement in vulnerable adolescents is underpinned by high inhibition, fewer social approach behaviors, low social skills, and previous dissatisfying social experiences, collectively discouraging social engagement [55]. Therefore, social interactions become both overwhelming and disappointing [40], i.e., stressful rather than rewarding. Repeated aversive social experiences create a learning environment where future experiences are not relished [56] and social withdrawal emerges. Therefore, the experiences of those with social anxiety disorder typify anhedonia, with social withdrawal, reduced positive anticipation of future events, and low reward and pleasure during social engagement. Since these patterns persist into adulthood, it is likely that low positive affect occurs in social circumstances alongside other mechanisms which maintain symptoms.

\section{Subjective Experiences of Social Environments and Low Positive Affect}

The SST implies several elements of subjective emotional experiences during social context not only maintain low positive affect, but also underpin the emergence of social anxiety. In other mental health disorders, different subjective emotional experiences are associated with positive affect. For example, subjective emotional appraisals of interactions may be more closely aligned with happiness in patients with schizophrenia than in healthy individuals [57•]. In a review of experience sampling studies, patients with schizophrenia report more in-the-moment positive affect when they were with others, compared to when they were alone, and report similar levels of positive affect to healthy volunteers during social interactions [32•]. Taken together, these studies suggest that patients with schizophrenia may be highly sensitized to their in-the-moment emotional experiences in social situations, similar to those with social anxiety. While other studies suggest patients may be reluctant to engage socially, when they do, their positive affect increases. Similar results are also reported for individuals with depression using experience sampling [58] and in patients with PTSD while viewing happy faces [59].

Perceptions of social defeat occur through perceived loss or inability to gain subjectively valued external sources and internal or external attacks of a social nature [60] and are linked to longer term well-being [61]. In humans, perceptions of social defeat encompass experiences such as bullying, low social status (e.g., lower standing role in a workplace), lower socio-economic status (reflecting financial status), and isolation or social "separateness." Perceptions of social defeat are transdiagnostic, but are particularly well represented in PTSD, depression, anxiety, and suicidality [62]. The experiences of many individuals with mental health disorders include stigma, difficulty in social situations, reduced financial stability, and affluence. Regardless of pre-existing symptoms, these perceived social defeats are related to low positive affect [63]. While there is limited consideration of low positive affect in social contexts for people with eating disorders, experiences of perceived social defeat could characterize factors considered important. For instance, less favorable social comparison and submissive behaviors are related to the severity of eating disorders [64]. Perceived stigma is also associated with poor outcomes during treatment in those with eating disorders [65], and perceptions of negative social comparison are central to many elements of anorexia [66]. Psychological interventions need to take these perceived social experiences into account when trying to address anhedonia. Feelings of shame and unfavorable social comparison are likely to impair recovery for all mental health disorders. Although reward neural circuits might be the convergence point for perceived social defeat experiences, social defeat represents a complex social cognitive construct which requires consideration independently from reward or anhedonia in social circumstances.

In summarizing the experiences of low positive affect during social situations, research has considered people with social anxiety, schizophrenia, depression, eating disorders, and PTSD. The neural systems underpinning social reward may be particularly sensitized during adolescence; however, they continue to be an important convergence point for many social experiences throughout adulthood. Low positive affect during social contexts may be an indicator of multiple subjective social-emotional experiences, including subjectively low social ability, disappointing social encounters, perceived social defeat, or misalignment between expectations and actual experiences. This highlights the complex nature of social situations. Perhaps people with mental health disorders are more vulnerable to low positive affect following ambiguous social encounters. Given that the focus of this line of research is subjective experiences, studies employ self-report [63, 64] or experience sampling methodologies $[54,58]$; of note is the study by Flores et al. [48••], which 
combined functional imaging and experience sampling. Experience sampling methodologies provide an in-themoment rating of emotions within a social context; this can be particularly important for mental health disorders where offline processing or recall of emotions is likely influenced by cognitive biases. Further investigation of subjective emotional experiences during social interactions may provide clues for clinicians to understand why individuals may be reluctant to engage socially. The in-the-moment experiences of social situations have implications for the learning that underpins the cognitive components of anhedonia.

\section{Anhedonia as Reduced Wanting}

Reduced drive, motivation, or effort expended for social interactions indicates the wanting element of the pleasure cycle [67]. This component of the cycle reflects the interaction between cognitive and emotional elements of social experiences. Past social experiences interact with cognitive constructs to shape the likelihood of engagement in future social experiences. Anticipation of future rewards is a key driver for human motivation [68]. Level of responsiveness to reward anticipation in the ventral striatum (during an incentive delay task with monetary and social reward) is associated with self-report social functioning transdiagnostically, in patients with schizophrenia, autistics spectrum, bipolar, and mood disorders [69]. Therefore, unsurprisingly, the ventral striatum appears to have transdiagnostic relevance for anticipation of rewards, common to social and other types of reward [70].

Reduced motivation for social rewards is reported in people with attention deficit hyperactivity disorder (ADHD) [71], although they have intact striatal response to social rewards, when compared to healthy controls [72]. Adults with autistic spectrum disorders, when compared to controls, also report lower anticipated pleasure for social interactions [73], although responsiveness to non-social rewards remains intact [74]. While behavioral results for autistic spectrum disorders are inconsistent [75], the diminished neural response for anticipation of social reward is replicated across studies [76, 77]. For patients with PTSD, male Vietnam veterans display both reduced motivation and effort to maintain the presence of social stimuli (attractive faces) [78]. A group of patients with heightened sensitivity to both anticipation and gaining of rewards are people with bipolar disorder. However, heightened reward anticipation is not specific to social circumstances; rather, it reflects a generally sensitized reward system $[79,80]$.

When asked to imagine different social scenarios, patients with schizophrenia, with negative symptoms, anticipate more intense negative emotions when compared to controls; however, in response to social inclusion scenarios, patients also anticipate less intense positive emotions than controls
[81]. In addition to diminished anticipation of future positive social events, when compared to controls, patients with schizophrenia are less motivated to increase the chances of a future positive social interaction or avoid a future negative social event [82]. In considering the putative risk trait schizotypy, those scoring highly on schizotypy are less incentivized to engage socially [83•]. Therefore, the reduced positive anticipation of future social interactions precedes the onset of a diagnosable clinical psychotic disorder.

A recent synthesis and meta-analysis concluded that evidence for reduced anticipation of social reward was most consistent for ADHD, autistic, and schizophrenia spectrum disorders [84•]. This certainly seems to be a representative conclusion for the state of the current literature. Reduced wanting is reflected in lower levels of motivation, fewer approach behaviors, decreased positive anticipation of future occurrences, diminished anticipation of rewards, and lower effort exerted. It could be that multiple avenues underpin reductions in wanting, or these constructs could all reflect outcomes of a similar underlying process. Methodologies differ across the studies cited here. Experimental methods include the incentive delay task (with social and monetary reward) $[71,76,79,80]$, social and monetary incentivized go/no go tasks [72, 74, 75], and implicit learning tasks [77]. These tasks provide controlled methods to assess mechanisms underpinning motivation and reward, often using faces as rewards, which may not be processed in the same manner across all disorders. Elman et al. [78] used button presses to keep attractive faces on the screen as an analog for approach behaviors. Attempts to provide the ecological validity missing from experimental tasks are provided by Minor et al. [83•]'s recording of audio snippets in the flow of daily life, capturing social moments in real time over two days. Experimental designs where participants need to engage in some form of interaction, simulated [81] or real [82], are likely to provide more nuanced information about emotional and cognitive biases related to social environments. Within the idealized conditions of most experimental tasks, "cold" cognitions often override the more real-world subjective experiences. Further studies need to be conducted across all mental health disorders, such as PTSD and eating disorders, to gain a transdiagnostic perspective of some of the excellent paradigms currently being used to investigate autism and schizophrenia. In addition, while characterizing the presence of reduced wanting is important, what drives the decreases in motivation, lower approach behaviors etc., need to be teased apart.

\section{Anhedonia as Faulty Learning and Failure in Emotional Connection}

The final element of the pleasure cycle is learning: linking past experiences to the appropriate emotional tag to ensure 
future social experiences are sought out [67]. Appraisals of social experiences feed into this component, which means disorder-specific cognitive biases influence outcomes. Learning is complex; it involves the appropriate and effective confluence of emotional and cognitive processes. While it is proposed that alterations to the pleasure cycle can be temporary [85], alterations to learning will be more difficult to ameliorate. These points mean that disorder-specific models have been developed rather than transdiagnostic frameworks. However, there are learning models which specifically consider social contexts; these will be outlined here.

\section{How Might Negative Affect Influence the Social Experiences?}

Two complementary theories provide an explanation for how negative affect might become a chronic barrier to enjoyment of social occasions: the Negative Affective Interference theory (NAIT) [86] and the Reward Devaluation Theory (RDT) [87] (see Fig. 1). The NAIT was devised specifically for patients with PTSD, who experience trauma within a social context, for example, abuse or domestic violence. Due to their traumatic experiences, positive external social experiences are perceived as threatening, reduced positive and increased negative affect mark subjective emotions subsequently marring subsequent social experiences. NAI predicts PTSD symptoms over and above depressive symptoms and explains why patients endorse lower positive valence in response to social images [86]. Anhedonic responses, while processing social contexts, activate the medial prefrontal cortex and right temporoparietal junction [88], suggesting functional brain changes underlie emotional alterations. Furthermore, future PTSD symptoms are predicted by brain areas involved in cognitive (cognitive control: Stroop task [89] and memory [90]) rather than emotional processing. Therefore, interfering effects of negative affect for social contexts may be cognitively mediated rather than emotionally driven. Similar to PTSD, in patients with depression, higher symptoms are related to increased connectivity between dorsal anterior cingulate cortex (cognitive control) and posterior cingulate cortex (internal attention) during a Stroop task; again emphasizing affective interference driven by cognitive mechanisms [91]. NAIT needs testing in other disorders where trauma is present, since trauma exposure alone does not explain reduced reward in people with PTSD [5].
Fig. 1 Two theories account for the emergence of negative affect during social experiences following negative experiences. A The Negative Affective Interference Model: trauma or an aversive experience mean that otherwise positive experiences are "tagged" as threatening and they then become associated with negative affect. B Reward Devaluation Theory: a series of aversive experiences following external events ensure negative emotions arise, making it more likely those experiences will be devalued and less likely to be repeated

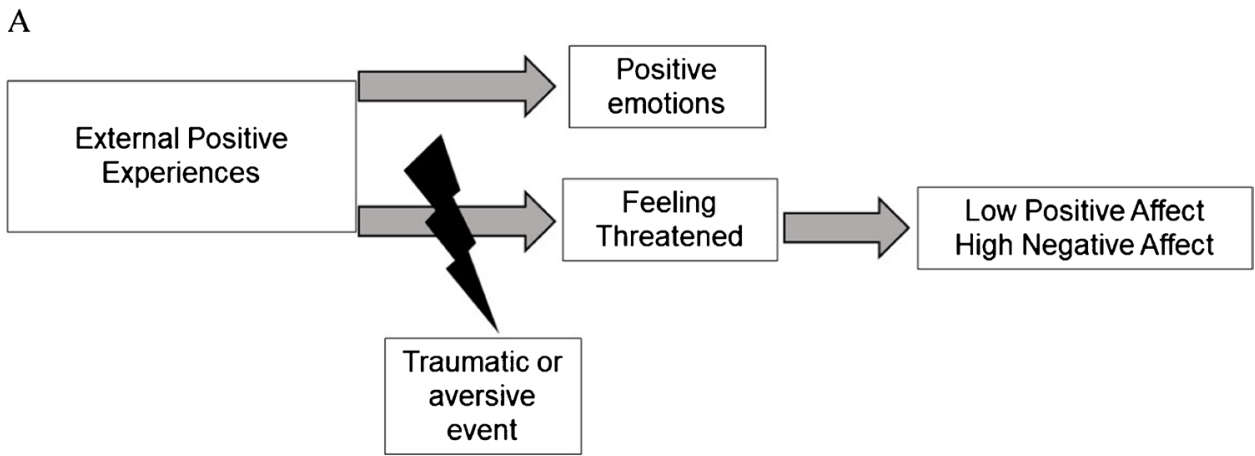

B

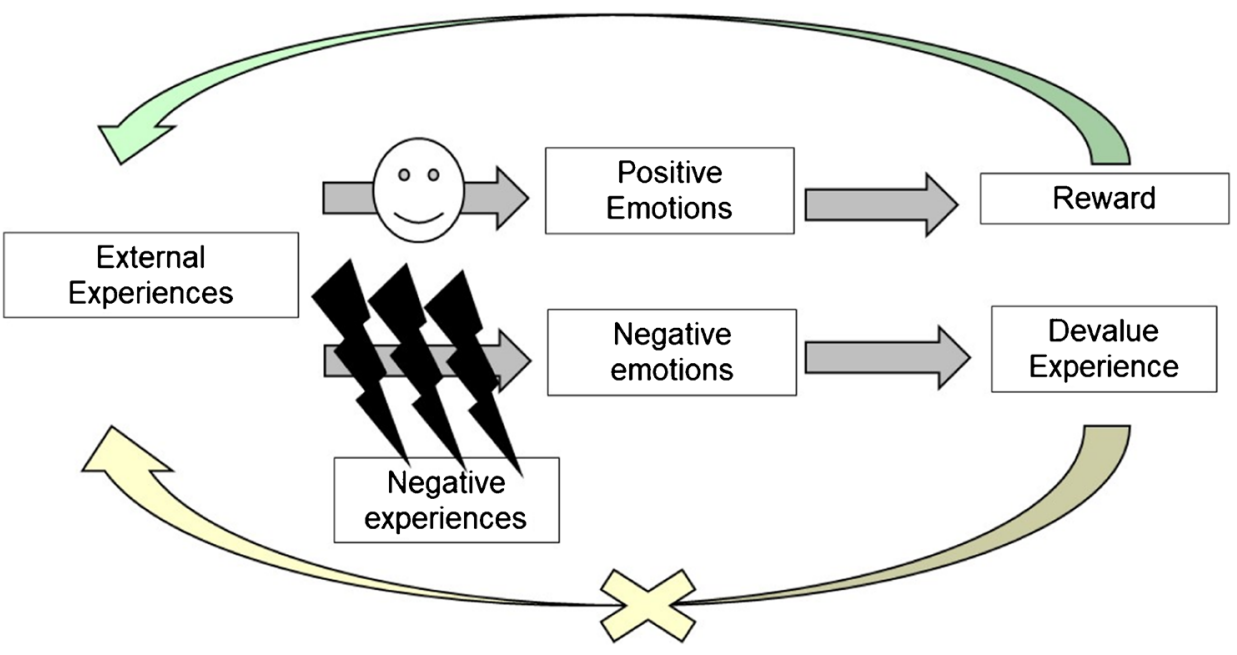


While the NAIT accounts for changes in in-the-moment emotional experience, it does not explain decreases in social approach behaviors. Instead, the RDT suggests people come to devalue rewarding experiences following repeated negative and disappointing outcomes. These negative experiences do not need to rise to the level of trauma; rather, attrition after repeated undesired experiences or outcomes from social contexts is sufficient. Therefore, RDT suggests negative emotions arise from the repeated disappointments, which lead, otherwise positive experiences, to be devalued and less likely repeated in the future. Correlates of RDT have been related to current [92•] and future [93] depressive symptoms. Although many studies testing RDT take a cognitive rather than social context, a recent study by Taylor et al. [94-] provides indirect evidence: lower positive valence and higher negative temperament were associated with reduced social connection in people seeking treatment for depression and anxiety.

NAIT is a learning theory since it pairs the association of experience and outcomes, while RDT takes this one step further and the feedback loop of devaluation decreases future social approach behaviors. These models are important for understanding anhedonia in a social context since NAIT and RDT provide complementary explanations for how a serious event, or numerous smaller negative occurrences, can impinge upon the subjective positive emotional gains from social contexts. While both emphasize how negative affect might arise in social contexts, only the RDT explains why social withdrawal might arise from repeated social letdowns or aversive experiences. Both models co-exist with one (NAIT) providing an explanation for what might arise following trauma and the other (RDT) reflecting evolution from repeated experiences, perhaps common to those with depression, anxiety, or even eating disorders.

\section{Predicting Future Emotions}

While the RDT provides one explanation for how negative experiences might shape future approach behaviors, the ability of affective forecasting is highly relevant to processing future social experiences. Future subjective emotional appraisals for similar or new experiences are predicted on the basis of past experience [95]. Given social context is represented cognitively [96], affective forecasting is highly germane to anhedonia. While affective forecasting has not been considered in relation to anhedonia generally, there are two recent studies concerned with social anhedonia (SA) which will be briefly mentioned [97•, 98]. Moore et al. [98] reported there were no differences for positive affect; however, those with high SA anticipated and experienced higher negative affect and predicted negative affect more accurately. Zhang et al. [97•] reported anticipated valence in social (but not non-social) conditions were associated with connectivity between the retrosplenial cortex and insula, and the hippocampus and parahippocampus. Those with higher SA had stronger and reduced connectivity, respectively, between these areas. Furthermore, people with SA anticipated less pleasure and had less visceral descriptions of anticipated events. These studies require replication with anhedonia, and affective forecasting deserves further consideration in psychopathology. Existing studies suggest people expressing SA are poor at positively representing future social events, and this impacts their capacity to look forward to and enjoy these experiences when they occur.

\section{Learning Theories Summarized and Future Directions}

The learning theories concerned with social contexts tend to be cognitively and experimentally driven, and often highlight the relative importance of cognitive over emotional processing. The theories tend to be driven by an interest in particular mental health disorders; however, the specificity of these models is yet to be tested and wider inclusion of different patient groups is needed in future studies. The reciprocal and transactional nature of social contexts is often missing from the paradigms used to test these models. However, one recent interesting task which appears to possess high ecological validity is the ultimatum game (see Fig. 2). There is an increasing and interesting literature on this task; a few examples of findings will be given here for illustrative purposes. In the game people are proposers or responders to financial deals; the deals vary in their fairness; similarly, the status of the "players" can vary. The game can be played dynamically with multiple responders and cooperation may be necessary for longer term success. Patients with depression [99], schizophrenia [100, 101], and bipolar [102] are more sensitive than controls to unfairness either subjectively or offers they accept, while low prosocial behaviors are predicted by fewer recent social contacts [103] or autistic spectrum disorder status [104]. This task is worthy of future inclusion given its high ecological validity and need for online decision making.

Unlike other studies summarized so far, learning models propose a mechanism which can be targeted with an intervention to lead to longer lasting changes for emotions experienced during social contexts. While the learning element is perhaps the most complex for understanding anhedonia in a social context, in many respects, it is the most important. It provides evidence of what may be underpinning experiences of low positive affect or reduced motivation rather than merely characterizing experiences. The learning models capture in a more nuanced fashion the interactions between cognitive and emotional processes which are relevant for anhedonia in a social context. With increasingly complex paradigms, such as the ultimatum game, experimental studies are becoming more sensitized to the transactional and online nature of social contexts. 


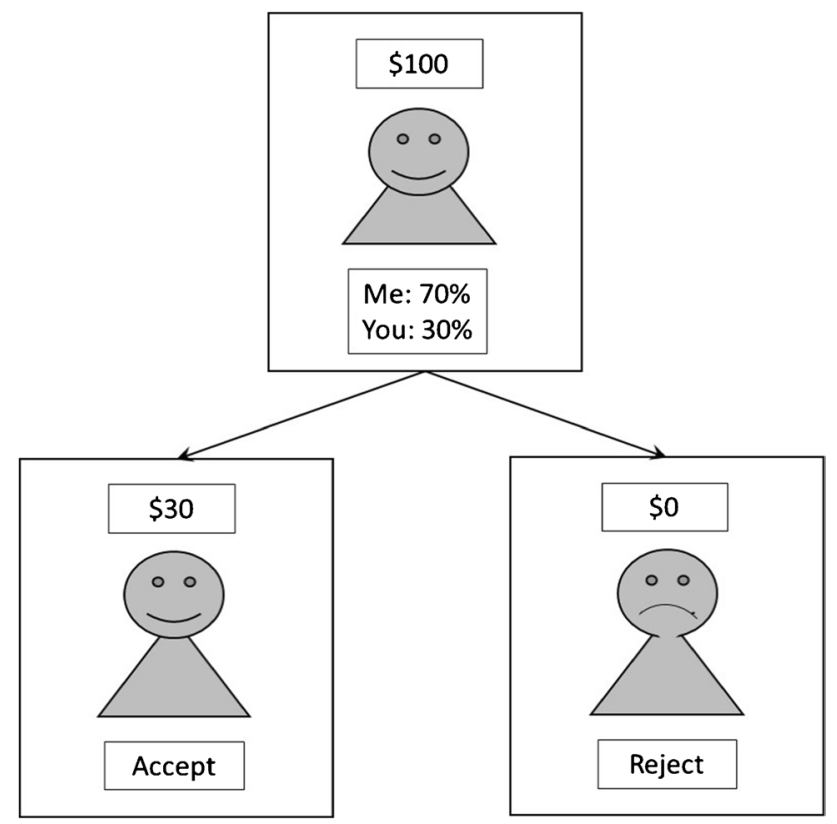

Fig. 2 The Ultimatum Game combines both cognitive and emotional elements to decision making. This creates conditions similar to dayto-day decisions. The game involves at least two characters; one character is a proposer and the other is a responder; in some versions of the task, there are multiple responders. The object of the game is to accrue as much money as possible. The proposer will put forward a division of the available money between themselves and the responder. The proposer always needs to offer the responder a share of the money available. The responder then decides whether to accept the division. If they accept, both parties receive their funds; if they reject, neither party will receive the money. Rejection of a proposal is thought to reflect punishment. Social influences on decision making drive responder's rejections of offers perceived to be unfair; the closer to a fair division of funds, the more likely it is that a responder will accept the proposal. There is no consensus on what is considered an unfair offer, although $40 \%$ and above to the responder is often used as the start of fair divisions in many studies. Proposers also tend to be inclined to offer fair division rather than a purely self-interested division (i.e., a significant proportion to themselves). This pattern of proposing and accepting is at odds with classical economy theory, where it is assumed that the proposer would offer the least possible amount to the responder, and the responder would view any funds as a gain. The proposer can be another participant or a simulated character. In some versions of the task, the proposer is aware of the responder's emotional assessment (fairness) of the proposal, while in other versions, the proposer is blind to this and is only aware of the decision to accept or reject

All future studies concerned with the learning mechanisms underpinning anhedonia in social contexts need to be mindful of the ecological validity of their scenarios and stimuli.

\section{Recommendations for Future Research}

This review has been by no means exhaustive in its inclusion of references; rather, attempts have been made to provide a representative selection of studies within each section for patients with mental health disorders where research has been performed. Certainly, past literature has emphasized anhedonia in social settings varyingly across diagnostic groups, usually aligned to the importance highlighted through diagnostic criteria. For instance, while there has been much work concerned with motivation and learning in eating disorders in relation to food, only more recently has social functioning and anhedonia in social settings received attention. Within PTSD, research emphasizes the intrusive nature of symptoms, while for depression, schizophrenia, and autism, there is a wider spread of self-report, experimental, and clinical research concerned with anhedonia in social contexts. Therefore, one key recommendation for future work is for transdiagnostic approaches within studies so theories and experimental paradigms can be applied to more than one mental health disorder simultaneously, and the mechanisms common, and unique, to different disorders better understood. From a self-report perspective, capturing of subjective ratings in the moment using experience sampling methodology needs to become more widely used, particularly in combination with experimental or imaging paradigms to begin to appreciate how experimental task performance relates to real-world subjective experiences.

Although reward has been extensively investigated, one element which appears unconsidered is the scope, range, or window of reward for each individual. Two examples may help clarify: first, in substance abuse, reward scope is narrowed to such an extent the substance becomes the only option for reward; the wanting of the drug of choice becomes the focus of reward at the expense of other more adaptive pleasurable experiences [85]. Second, vulnerability to developing callous and unemotional traits occurs when the learning environment provides a backdrop for an interaction between low reward from social connection and reduced perceived social threat [105]. Under these circumstances, the sensitized window for reward anticipation both shifts and reflects less prosocial behavior [106]. Future research needs to develop an understanding of individual differences in the value, pleasure, and reward attached to various social contexts. Some studies in the current review highlight that those with depression and social anxiety have preferences for their social circumstances [35, 39, 40]; it may be that those with mental health disorders have strong preferences for aligning their needs and their social environment.

There is also room for clarification for how anhedonia in the social context might overlap other physical and emotional concepts. Some definitions of anhedonia include low energy [107] and weariness and fatigue [108, 109]. Fatigue and anhedonia may have both shared and distinct underlying mechanisms [110]. Neurobiologically, inflammation [111, 112] and dopamine [113] may represent common pathways for both fatigue and anhedonia, while serotonin might be more specific to fatigue [113]. The overwhelming nature 
of symptoms in mental health disorders suggests fatigue is likely and reduces pleasure capacity. For example, consider anxiety disorders [114] and PTSD [115], heightened levels of anxiety, hypervigilance, and intrusive symptoms readily create physically taxing experiences in social circumstances. Future studies need to consider fatigue in those with mental health disorders in social contexts to distinguish its consequences from anhedonia.

Labeling of emotions is also complex, with low ability to label emotions [116] and the cultural context of socialemotional experiences being largely ignored to date. Culture shapes the language available for people to use as well as acceptable behaviors and permitted expectations. Affect is regulated by strategies that reflect socially bound and culturally derived values [117]. For example, having higher positive affect while preserving social harmony was important for health outcomes in Japanese adults, while social connectedness was not related to health outcomes in adults from the USA [118]. Interestingly, in the same study, the association between positive affect and health outcomes was significant for adults from the USA but not for those from Japan. Therefore, while clinicians consider cultural context in diagnostic matters, researchers now need to acknowledge the relevance of culture in theories and cross-study comparison.

\section{Conclusions}

It is becoming increasingly recognized that anhedonia is not exclusive to mood disorders. However, interest in anhedonia and its influence on experiences of social contexts needs to extend equally across all disorders, regardless of the emphasis placed by diagnostic categories. A consensus needs to be reached for a unified transdiagnostic definition of what is encompassed by anhedonia; this will be useful to clinicians in assisting patients with their experiences as well as researchers in framing their implications. Social contexts contain many factors which thwart and preserve mental well-being. The processes underpinning anhedonia shape the anticipation and in-the-moment experiences during social interactions. Preferences for social environments are considered a healthy reflection of individual differences in the general population, these now need extending to people with mental health disorders. Anhedonia is likely to heighten underlying temperament factors that shape social preferences.

Future theory development needs to reflect that anhedonia is a transdiagnostic symptom; therefore, explanations need to go beyond reward processing to provide cognitive, social, and emotional processes that are applicable to universal human experience. With increased understanding of the detrimental effects of low social connectedness or loneliness for mental and physical health, any factors which threaten opportunities for meaningful social connections need to be ameliorated. An understanding of how anhedonia shapes subjective experiences in social settings will not only move forward interventions for mental health disorders but also transient experiences of low social rewards in the general healthy population. Understanding the nature of social reward is paramount for the development of targeted, evidence-based interventions which promote psychological health and recovery from mental health disorders. Therefore, increased knowledge on how anhedonia interferes with the experience of social contexts should be a priority for clinicians, researchers, and social policymakers in reducing the individual and economic burden of mental ill-health.

Open Access This article is licensed under a Creative Commons Attribution 4.0 International License, which permits use, sharing, adaptation, distribution and reproduction in any medium or format, as long as you give appropriate credit to the original author(s) and the source, provide a link to the Creative Commons licence, and indicate if changes were made. The images or other third party material in this article are included in the article's Creative Commons licence, unless indicated otherwise in a credit line to the material. If material is not included in the article's Creative Commons licence and your intended use is not permitted by statutory regulation or exceeds the permitted use, you will need to obtain permission directly from the copyright holder. To view a copy of this licence, visit http://creativecommons.org/licenses/by/4.0/.

\section{References}

Papers of particular interest, published recently, have been highlighted as:

- Of importance

$\bullet$ Of major importance

1. APA. Diagnostic and statistical manual of mental disorders: DSM-5 ${ }^{\text {TM }}$, 5th ed. Diagnostic and statistical manual of mental disorders: DSM-5 ${ }^{\mathrm{TM}}$, 5th ed. Arlington, VA, US: American Psychiatric Publishing, Inc.; 2013.

2. Horan WP, Kring AM, Gur RE, Reise SP, Blanchard JJ. Development and psychometric validation of the Clinical Assessment Interview for Negative Symptoms (CAINS). Schizophr Res. 2011;132(2-3):140-5. https://doi.org/10.1016/j. schres.2011. 06.030 .

3. Winer ES, Bryant J, Bartoszek G, Rojas E, Nadorff MR, Kilgore J. Mapping the relationship between anxiety, anhedonia, and depression. J Affect Disord. 2017;221:289-96. https://doi.org/ 10.1016/j.jad.2017.06.006.

4. Pushkarskaya H, Sobowale K, Henick D, Tolin DF, Anticevic A, Pearlson GD, et al. Contrasting contributions of anhedonia to obsessive-compulsive, hoarding, and post-traumatic stress disorders. J Psychiatr Res. 2019;109:202-13. https://doi.org/ 10.1016/j.jpsychires.2018.11.029.

5. Nawijn L, van Zuiden M, Frijling JL, Koch SB, Veltman DJ, Olff M. Reward functioning in PTSD: a systematic review exploring the mechanisms underlying anhedonia. Neurosci Biobehav Rev. 2015;51:189-204. https://doi.org/10.1016/j.neubiorev.2015.01. 019. 
6. Kashdan TB, Elhai JD, Frueh BC. Anhedonia and emotional numbing in combat veterans with PTSD. Behav Res Ther. 2006;44(3):457-67. https://doi.org/10.1016/j.brat.2005.03.001.

7. Santonicola A, Gagliardi M, Asparago G, Carpinelli L, Angrisani L, Iovino P. Anhedonia and functional dyspepsia in obese patients: relationship with binge eating behaviour. World J Gastroenterol. 2020;26(20):2632-44. https://doi.org/10.3748/ wjg.v26.i20.2632.

8. Harrison A, Mountford VA, Tchanturia K. Social anhedonia and work and social functioning in the acute and recovered phases of eating disorders. Psychiatry Res. 2014;218(1-2):187-94. https:// doi.org/10.1016/j.psychres.2014.04.007.

9. Arcelus J, Haslam M, Farrow C, Meyer C. The role of interpersonal functioning in the maintenance of eating psychopathology: a systematic review and testable model. Clin Psychol Rev. 2013;33(1):156-67. https://doi.org/10.1016/j.cpr.2012.10.009.

10. Pelizza L, Ferrari A. Anhedonia in schizophrenia and major depression: state or trait? Ann Gen Psychiatry. 2009;8:22. https://doi.org/10.1186/1744-859x-8-22.

11. Li Y, Mou X, Jiang W, Yang Z, Shen X, Jin Z, et al. A comparative study of anhedonia components between major depression and schizophrenia in Chinese populations. Ann Gen Psychiatry. 2015;14:24. https://doi.org/10.1186/s12991-015-0061-3.

12.• Ducasse D, Loas G, Dassa D, Gramaglia C, Zeppegno P, Guillaume $\mathrm{S}$, et al. Anhedonia is associated with suicidal ideation independently of depression: a meta-analysis. Depress Anxiety. 2018;35(5):382-92. https://doi.org/10.1002/da.22709. Comprehensive meta-analysis which considers the association between anhedonia and current suidicuidality in an impressively large sample size.

13.• Yang X, Wang D, Liu S, Liu G, Harrison P. Stress and suicidal ideation: the role of state or trait anhedonia in a moderated mediation model. Suicide Life Threat Behav. 2020;50(2):50214. https://doi.org/10.1111/sltb.12605. Differentiates between state and trait anhedonia for associations with suidicality to report that both are important predictors.

14. Boehm I, Flohr L, Steding J, Holzapfel L, Seitz J, Roessner V, et al. The trajectory of anhedonic and depressive symptoms in anorexia nervosa: a longitudinal and cross-sectional approach. Eur Eat Disord Rev. 2018;26(1):69-74. https://doi.org/10.1002/ erv.2565.

15. Loas G, Monestes JL, Ingelaere A, Noisette C, Herbener ES. Stability and relationships between trait or state anhedonia and schizophrenic symptoms in schizophrenia: a 13-year follow-up study. Psychiatry Res. 2009;166(2-3):132-40. https://doi.org/ 10.1016/j.psychres.2008.02.010.

16. Pelizza L, Poletti M, Azzali S, Paterlini F, Garlassi S, Scazza I, et al. Anhedonia in adolescents at ultra-high risk (UHR) of psychosis: findings from a 1-year longitudinal study. Eur Arch Psychiatry Clin Neurosci. 2020;270(3):337-50. https://doi.org/ 10.1007/s00406-019-01018-9.

17. Marder SR, Galderisi S. The current conceptualization of negative symptoms in schizophrenia. World Psychiatry. 2017;16(1):14-24. https://doi.org/10.1002/wps.20385.

18. Barkus E, Badcock JC. A Transdiagnostic perspective on social anhedonia. Frontiers in Psychiatry. 2019;10(216). doi:https://doi. org/10.3389/fpsyt.2019.00216.

19. Chapman LJ, Chapman JP, Raulin ML. Scales for physical and social anhedonia. J Abnorm Psychol. 1976;85(4):374-82.

20. Fawcett J, Clark DC, Scheftner WA, Gibbons RD. Assessing anhedonia in psychiatric patients. Arch Gen Psychiatry. 1983;40(1):79-84. https://doi.org/10.1001/archpsyc.1983.01790 010081010 .

21. Snaith RP, Hamilton M, Morley S, Humayan A, Hargreaves D, Trigwell P. A scale for the assessment of hedonic tone the Snaith-Hamilton Pleasure Scale. The British journal of psychiatry: the journal of mental science. 1995;167(1):99-103. https://doi.org/10.1192/bjp.167.1.99.

22. Gard DE, Gard MG, Kring AM, John OP. Anticipatory and consummatory components of the experience of pleasure: a scale development study. J Res Pers. 2006;40(6):1086-102. https:// doi.org/10.1016/j.jrp.2005.11.001

23. Llerena K, Park SG, McCarthy JM, Couture SM, Bennett ME, Blanchard JJ. The Motivation and Pleasure Scale-Self-Report (MAP-SR): reliability and validity of a self-report measure of negative symptoms. Compr Psychiatry. 2013;54(5):568-74. https://doi.org/10.1016/j.comppsych.2012.12.001.

24. Gooding DC, Pflum MJ. The assessment of interpersonal pleasure: introduction of the Anticipatory and Consummatory Interpersonal Pleasure Scale (ACIPS) and preliminary findings. Psychiatry Res. 2014;215(1):237-43. https://doi.org/ 10.1016/j.psychres.2013.10.012.

25. Winer ES, Veilleux JC, Ginger EJ. Development and validation of the Specific Loss of Interest and Pleasure Scale (SLIPS). J Affect Disord. 2014;152-154:193-201. https://doi.org/10. 1016/j.jad.2013.09.010.

26. Yang Y, Yang ZY, Zou YM, Shi HS, Wang Y, Xie DJ, et al. Low-pleasure beliefs in patients with schizophrenia and individuals with social anhedonia. Schizophr Res. 2018;201:13744. https://doi.org/10.1016/j.schres.2018.05.018.

27. Khazanov GK, Ruscio AM, Forbes CN. The positive valence systems scale: development and validation. Assessment. 2020;27(5):1045-69. https://doi.org/10.1177/1073191119 869836.

28. Lamblin M, Murawski C, Whittle S, Fornito A. Social connectedness, mental health and the adolescent brain. Neurosci Biobehav Rev. 2017;80:57-68. https://doi.org/10.1016/j.neubi orev.2017.05.010.

29. Hutcherson CA, Seppala EM, Gross JJ. The neural correlates of social connection. Cogn Affect Behav Neurosci. 2015;15(1):1-14. https://doi.org/10.3758/s13415-014-0304-9.

30. Chavez RS, Wagner DD. The neural representation of self is recapitulated in the brains of friends: a round-robin fMRI study. J Pers Soc Psychol. 2020;118(3):407-16. https://doi. org/10.1037/pspa0000178. Highlights how the neural representations of the self are shared by close friends.

31. Morgan VA, Waterreus A, Carr V, Castle D, Cohen M, Harvey C, et al. Responding to challenges for people with psychotic illness: updated evidence from the survey of high impact psychosis. Aust N Z J Psychiatry. 2017;51(2):124-40. https://doi. org/10.1177/0004867416679738.

32. Mote J, Fulford D. Ecological momentary assessment of everyday social experiences of people with schizophrenia: a systematic review. Schizophr Res. 2020;216:56-68. https://doi.org/ 10.1016/j.schres.2019.10.021. Summarises the results from experience sampling studies with patients with schizophrenia. Importantly, across multiple studies patients with schizophrenia report similar positive affect to controls during social interactions.

33. Igbokwe CC, Ejeh VJ, Agbaje OS, Umoke PIC, Iweama $\mathrm{CN}$, Ozoemena EL. Prevalence of loneliness and association with depressive and anxiety symptoms among retirees in Northcentral Nigeria: a cross-sectional study. BMC Geriatr. 2020;20(1):153. https://doi.org/10.1186/s12877-020-01561-4.

34. Schneider M, Reininghaus U, van Nierop M, Janssens M, Myin-Germeys I. Does the Social Functioning Scale reflect real-life social functioning? An experience sampling study in patients with a non-affective psychotic disorder and healthy control individuals. Psychol Med. 2017;47(16):2777-86. https://doi.org/10.1017/s0033291717001295.

35. Elmer T, Stadtfeld C. Depressive symptoms are associated with social isolation in face-to-face interaction 
networks. Sci Rep. 2020;10(1):1444. https://doi.org/10.1038/ s41598-020-58297-9.

36. Mason TB, Smith KE, Anderson LM, Hazzard VM. Anhedonia, positive affect dysregulation, and risk and maintenance of bingeeating disorder. Int J Eat Disord. 2020. https://doi.org/10.1002/ eat.23433.

37. Courty A, Godart N, Lalanne C, Berthoz S. Alexithymia, a compounding factor for eating and social avoidance symptoms in anorexia nervosa. Compr Psychiatry. 2015;56:217-28. https:// doi.org/10.1016/j.comppsych.2014.09.011.

38. Coniglio KA, Christensen KA, Haynos AF, Rienecke RD, Selby EA. The posited effect of positive affect in anorexia nervosa: advocating for a forgotten piece of a puzzling disease. Int J Eat Disord. 2019;52(9):971-6. https://doi.org/10.1002/eat.23147.

39. Faytout M, Swendsen J. Phobie sociale et vie quotidienne. Journal de Thérapie Comportementale et Cognitive. 2009;19(3):88-92. https://doi.org/10.1016/j.jtcc.2009.08.004.

40. Russell JJ, Moskowitz DS, Zuroff DC, Bleau P, Pinard G, Young SN. Anxiety, emotional security and the interpersonal behavior of individuals with social anxiety disorder. Psychol Med. 2011;41(3):545-54. https://doi.org/10.1017/s003329171 0000863.

41. Kashdan TB, Goodman FR, Machell KA, Kleiman EM, Monfort SS, Ciarrochi J, et al. A contextual approach to experiential avoidance and social anxiety: evidence from an experimental interaction and daily interactions of people with social anxiety disorder. Emotion (Washington, DC). 2014;14(4):76981. https://doi.org/10.1037/a0035935.

42. Teo AR, Lerrigo R, Rogers MA. The role of social isolation in social anxiety disorder: a systematic review and meta-analysis. J Anxiety Disord. 2013;27(4):353-64. https://doi.org/10. 1016/j.janxdis.2013.03.010.

43. Watson D, Naragon-Gainey K. On the specificity of positive emotional dysfunction in psychopathology: evidence from the mood and anxiety disorders and schizophrenia/schizotypy. Clin Psychol Rev. 2010;30(7):839-48. https://doi.org/ 10.1016/j.cpr.2009.11.002.

44. Der-Avakian A, Markou A. The neurobiology of anhedonia and other reward-related deficits. Trends Neurosci. 2012;35(1):6877. https://doi.org/10.1016/j.tins.2011.11.005.

45. Buckner JD, Lewis EM, Walukevich-Dienst K. Drinking problems and social anxiety among young adults: the roles of drinking to manage negative and positive affect in social situations. Subst Use Misuse. 2019;54(13):2117-26. https:// doi.org/10.1080/10826084.2019.1637892.

46. Vranceanu AM, Gallo LC, Bogart LM. Depressive symptoms and momentary affect: the role of social interaction variables. Depress Anxiety. 2009;26(5):464-70. https://doi.org/10.1002/ da.20384.

47. Silverman MH, Jedd K, Luciana M. Neural networks involved in adolescent reward processing: an activation likelihood estimation meta-analysis of functional neuroimaging studies. Neuroimage. 2015;122:427-39. https://doi.org/10.1016/j.neuro image.2015.07.083.

48.•• Flores LE Jr, Eckstrand KL, Silk JS, Allen NB, Ambrosia M, Healey KL, et al. Adolescents' neural response to social reward and real-world emotional closeness and positive affect. Cogn Affect Behav Neurosci. 2018;18(4):705-17. https://doi. org/10.3758/s13415-018-0598-0. Links neural responsess to social reward to interactions in the flow of everyday life to report how those with high and low reward responsiveness differ in their experience of everyday emotional closeness.

49. Patel GH, Sestieri C, Corbetta M. The evolution of the temporoparietal junction and posterior superior temporal sulcus. Cortex; a journal devoted to the study of the nervous system and behavior. 2019;118:38-50. https://doi.org/10.1016/j.cortex.2019.01.026.

50. Smith DV, Clithero JA, Boltuck SE, Huettel SA. Functional connectivity with ventromedial prefrontal cortex reflects subjective value for social rewards. Soc Cogn Affect Neurosci. 2014;9(12):2017-25. https://doi.org/10.1093/scan/nsu005.

51. Kashdan TB. Social anxiety spectrum and diminished positive experiences: theoretical synthesis and meta-analysis. Clin Psychol Rev. 2007;27(3):348-65. https://doi.org/10.1016/j.cpr. 2006.12.003.

52. Weisman JS, Rodebaugh TL, Brown PJ, Mulligan EA. Positive affect and social anxiety across the lifespan: an investigation of age as a moderator. Clin Gerontol. 2015;38(1):1-18. https:// doi.org/10.1080/07317115.2014.970317.

53. Richey JA, Brewer JA, Sullivan-Toole H, Strege MV, KimSpoon J, White SW, et al. Sensitivity shift theory: a developmental model of positive affect and motivational deficits in social anxiety disorder. Clin Psychol Rev. 2019;72: 101756. https://doi.org/10.1016/j.cpr.2019.101756.

54. Morgan JK, Lee GE, Wright AGC, Gilchrist DE, Forbes EE, McMakin DL, et al. Altered positive affect in clinically anxious youth: the role of social context and anxiety subtype. J Abnorm Child Psychol. 2017;45(7):1461-72. https://doi.org/ 10.1007/s10802-016-0256-3.

55. Greco LA, Morris TL. Factors influencing the link between social anxiety and peer acceptance: contributions of social skills and close friendships during middle childhood. Behav Ther. 2005;36(2):197-205. https://doi.org/10.1016/S00057894(05)80068-1.

56. Glenn JJ, Chow PI, Teachman BA. How badly will I feel if you don't like me?: social anxiety and predictions of future affect. J Soc Clin Psychol. 2019;38(3):245-75. https://doi.org/10.1521/ jscp.2019.38.3.245.

57. Mote J, Gard DE, Gonzalez R, Fulford D. How did that interaction make you feel? The relationship between quality of everyday social experiences and emotion in people with and without schizophrenia. PLoS ONE. 2019;14(9): e0223003. https:// doi.org/10.1371/journal.pone.0223003. Data collected during the flow of everyday life outlines how the qualities of social interactions are more important to affect in patients with schizophrenia than controls.

58. Brown LH, Strauman T, Barrantes-Vidal N, Silvia PJ, Kwapil TR. An experience-sampling study of depressive symptoms and their social context. J Nerv Ment Dis. 2011;199(6):403-9. https://doi.org/10.1097/NMD.0b013e31821cd24b.

59. Steuwe C, Daniels JK, Frewen PA, Densmore M, Pannasch S, Beblo T, et al. Effect of direct eye contact in PTSD related to interpersonal trauma: an fMRI study of activation of an innate alarm system. Social Cognitive and Affective Neuroscience. 2012;9(1):88-97. https://doi.org/10.1093/scan/nss105.

60. Gilbert P. Varieties of submissive behavior as forms of social defense: their evolution and role in depression. Subordination and defeat: an evolutionary approach to mood disorders and their therapy. Mahwah, NJ, US: Lawrence Erlbaum Associates Publishers; 2000. p. 3-45.

61. Moore SE, Norman RE, Suetani S, Thomas HJ, Sly PD, Scott JG. Consequences of bullying victimization in childhood and adolescence: a systematic review and meta-analysis. World $\mathbf{J}$ Psychiatry. 2017;7(1):60-76. https://doi.org/10.5498/wjp.v7. i1.60.

62. Siddaway AP, Taylor PJ, Wood AM, Schulz J. A meta-analysis of perceptions of defeat and entrapment in depression, anxiety problems, posttraumatic stress disorder, and suicidality. $\mathbf{J}$ Affect Disord. 2015;184:149-59. https://doi.org/10.1016/j.jad. 2015.05.046. 
63. Gilbert P, Allan S, Brough S, Melley S, Miles JN. Relationship of anhedonia and anxiety to social rank, defeat and entrapment. J Affect Disord. 2002;71(1-3):141-51. https://doi.org/ 10.1016/s0165-0327(01)00392-5.

64. Troop NA, Allan S, Treasure JL, Katzman M. Social comparison and submissive behaviour in eating disorder patients. Psychol Psychother. 2003;76(Pt 3):237-49. https://doi.org/10. 1348/147608303322362479.

65. Dimitropoulos G, McCallum L, Colasanto M, Freeman VE, Gadalla T. The effects of stigma on recovery attitudes in people with anorexia nervosa in intensive treatment. J Nerv Ment Dis. 2016;204(5):370-80. https://doi.org/10.1097/nmd.00000 00000000480 .

66. Munro C, Randell L, Lawrie SM. An integrative bio-psychosocial theory of anorexia nervosa. Clin Psychol Psychother. 2017;24(1):1-21. https://doi.org/10.1002/cpp.2047.

67. Berridge KC, Robinson TE, Aldridge JW. Dissecting components of reward: 'liking', 'wanting', and learning. Curr Opin Pharmacol. 2009;9(1):65-73. https://doi.org/10.1016/j.coph. 2008.12.014.

68. McClure SM, Laibson DI, Loewenstein G, Cohen JD. Separate neural systems value immediate and delayed monetary rewards. Science. 2004;306(5695):503-7. https://doi.org/10. 1126/science. 1100907.

69. Schwarz K, Moessnang C, Schweiger JI, Baumeister S, Plichta MM, Brandeis D, et al. Transdiagnostic Prediction of affective, cognitive, and social function through brain reward anticipation in schizophrenia, bipolar disorder, major depression, and autism spectrum diagnoses. Schizophr Bull. 2020;46(3):592602. https://doi.org/10.1093/schbul/sbz075.

70. Izuma K, Saito DN, Sadato N. Processing of social and monetary rewards in the human striatum. Neuron. 2008;58(2):28494. https://doi.org/10.1016/j.neuron.2008.03.020.

71. Demurie E, Roeyers H, Baeyens D, Sonuga-Barke E. Common alterations in sensitivity to type but not amount of reward in ADHD and autism spectrum disorders. J Child Psychol Psychiatry. 2011;52(11):1164-73. https://doi.org/10.1111/j.14697610.2010.02374.x

72. Kohls G, Thönessen H, Bartley GK, Grossheinrich N, Fink GR, Herpertz-Dahlmann B, et al. Differentiating neural reward responsiveness in autism versus ADHD. Dev Cogn Neurosci. 2014;10:104-16. https://doi.org/10.1016/j.den.2014.08.003.

73. Han GT, Tomarken AJ, Gotham KO. Social and nonsocial reward moderate the relation between autism symptoms and loneliness in adults with ASD, depression, and controls. Autism Res. 2019;12(6):884-96. https://doi.org/10.1002/aur. 2088.

74. Kohls G, Schulte-Rüther M, Nehrkorn B, Müller K, Fink GR, Kamp-Becker I, et al. Reward system dysfunction in autism spectrum disorders. Soc Cogn Affect Neurosci. 2013;8(5):56572. https://doi.org/10.1093/scan/nss033.

75. Pankert A, Pankert K, Herpertz-Dahlmann B, Kon$\operatorname{rad} \mathrm{K}$, Kohls G. Responsivity to familiar versus unfamiliar social reward in children with autism. J Neural Transm (Vienna). 2014;121(9):1199-210. https://doi.org/10.1007/ s00702-014-1210-6.

76. Barman A, Richter S, Soch J, Deibele A, Richter A, Assmann A, et al. Gender-specific modulation of neural mechanisms underlying social reward processing by Autism Quotient. Soc Cogn Affect Neurosci. 2015;10(11):1537-47. https://doi.org/10.1093/ scan/nsv044.

77. Scott-Van Zeeland AA, Dapretto M, Ghahremani DG, Poldrack RA, Bookheimer SY. Reward processing in autism. Autism Res. 2010;3(2):53-67. https://doi.org/10.1002/aur.122.

78. Elman I, Ariely D, Mazar N, Aharon I, Lasko NB, Macklin ML, et al. Probing reward function in post-traumatic stress disorder with beautiful facial images. Psychiatry Res. 2005;135(3):179_ 83. https://doi.org/10.1016/j.psychres.2005.04.002.

79. Dutra SJ, Cunningham WA, Kober H, Gruber J. Elevated striatal reactivity across monetary and social rewards in bipolar I disorder. J Abnorm Psychol. 2015;124(4):890-904. https://doi. org/10.1037/abn0000092.

80. Dutra SJ, Man V, Kober H, Cunningham WA, Gruber J. Disrupted cortico-limbic connectivity during reward processing in remitted bipolar I disorder. Bipolar Disord. 2017;19(8):661-75. https://doi.org/10.1111/bdi.12560.

81. Engel M, Fritzsche A, Lincoln TM. Anticipation and experience of emotions in patients with schizophrenia and negative symptoms. An experimental study in a social context. Schizophr Res. 2016;170(1):191-7. doi:https://doi.org/10.1016/j.schres.2015. 11.028 .

82. Campellone TR, Truong B, Gard D, Schlosser DA. Social motivation in people with recent-onset schizophrenia spectrum disorders. J Psychiatr Res. 2018;99:96-103. https://doi.org/10.1016/j. jpsychires.2018.01.006.

83. Minor KS, Hardin KL, Beaudette DM, Waters LC, White AL, Gonzenbach V, et al. Social functioning in schizotypy: how affect influences social behavior in daily life. J Clin Psychol. 2020;76(12):2212-21. https://doi.org/10.1002/jclp.23010. Results suggest that those scoring high on schizotypy are not able to use past positive social interactions to senstivise future social engagement.

84. Aldridge-Waddon L, Vanova M, Munneke J, Puzzo I, Kumari V. Atypical social reward anticipation as a transdiagnostic characteristic of psychopathology: a meta-analytic review and critical evaluation of current evidence. Clin Psychol Rev. 2020;82: 101942. https://doi.org/10.1016/j.cpr.2020.101942. Comprehensive review which outlines that wider elements of psychopathology need consideration in accounting for the presence of reward anticipation abnormalities.

85. Rømer Thomsen K, Whybrow PC, Kringelbach ML. Reconceptualizing anhedonia: novel perspectives on balancing the pleasure networks in the human brain. Frontiers in behavioral neuroscience. 2015;9:49-. doi:https://doi.org/10.3389/fnbeh. 2015.00049.

86. DePierro J, D'Andrea W, Frewen P, Todman M. Alterations in positive affect: relationship to symptoms, traumatic experiences, and affect ratings. Psychol Trauma. 2018;10(5):585-93. https:// doi.org/10.1037/tra0000317.

87. Winer ES, Salem T. Reward devaluation: dot-probe meta-analytic evidence of avoidance of positive information in depressed persons. Psychol Bull. 2016;142(1):18-78. https://doi.org/10. 1037/bul0000022.

88. Frewen PA, Dozois DJA, Lanius RA. Assessment of anhedonia in psychological trauma: psychometric and neuroimaging perspectives. Eur J Psychotraumatol. 2012;3:https://doi.org/10. 3402/ejpt.v3i0.8587. doi:https://doi.org/10.3402/ejpt.v3i0.8587.

89. White SF, Costanzo ME, Thornton LC, Mobley AM, Blair JR, Roy MJ. Increased cognitive control and reduced emotional interference is associated with reduced PTSD symptom severity in a trauma-exposed sample: a preliminary longitudinal study. Psychiatry Res Neuroimaging. 2018;278:7-12. https://doi.org/ 10.1016/j.pscychresns.2018.06.006.

90. Malivoire BL, Girard TA, Patel R, Monson CM. Functional connectivity of hippocampal subregions in PTSD: relations with symptoms. BMC Psychiatry. 2018;18(1):129. https://doi.org/10. 1186/s12888-018-1716-9.

91. Kaiser RH, Andrews-Hanna JR, Spielberg JM, Warren SL, Sutton BP, Miller GA, et al. Distracted and down: neural mechanisms of affective interference in subclinical depression. Social Cognitive and Affective Neuroscience. 2014;10(5):654-63. https://doi.org/10.1093/scan/nsu100. 
92.• Jordan DG, Collins AC, Dunaway MG, Kilgore J, Winer ES. Negative affect interference and fear of happiness are independently associated with depressive symptoms. J Clin Psychol. 2020. https://doi.org/10.1002/jclp.23066. Tested both the negative affective interference and reward devaluation theories and found that both are important for predicting future depressive symptoms.

93. Jordan DG, Winer ES, Salem T, Kilgore J. Longitudinal evaluation of anhedonia as a mediator of fear of positive evaluation and other depressive symptoms. Cogn Emot. 2018;32(7):1437-47. https://doi.org/10.1080/02699931.2017.1289895.

94. Taylor CT, Pearlstein SL, Stein MB. A tale of two systems: testing a positive and negative valence systems framework to understand social disconnection across anxiety and depressive disorders. J Affect Disord. 2020;266:207-14. https://doi.org/ 10.1016/j.jad.2020.01.041. Outlines that both positive and negative affect are equally as important for subjective social connection.

95. Gilbert DT, Wilson TD. Prospection: experiencing the future. Science. 2007;317(5843):1351-4. https://doi.org/10.1126/scien ce. 1144161.

96. Bell V, Mills KL, Modinos G, Wilkinson S. Rethinking social cognition in light of psychosis: reciprocal implications for cognition and psychopathology. Clinical Psychological Science. 2017;5(3):537-50. https://doi.org/10.1177/2167702616677079.

97. Zhang R-t, Yang Z-y, Wang Y-m, Wang Y, Yang T-X, Cheung $\mathrm{EFC}$ et al. Affective forecasting in individuals with social anhedonia: the role of social components in anticipated emotion, prospection and neural activation. Schizophrenia Research. 2020;215:322-9. doi:https://doi.org/10.1016/j.schres.2019.10. 006. Highlights how valence for social situations was related to connections between reward relevant brain regions.

98. Moore MM, Chan RCK, Huang J, Martin EA. Affective forecasting and accuracy in social anhedonia: predicted and experienced emotion for a social interaction. J Clin Psychol. 2019;75(9):1684-700. https://doi.org/10.1002/jclp.22796.

99. Hu Y, Zhou M, Shao Y, Wei J, Li Z, Xu S, et al. The effects of social comparison and depressive mood on adolescent social decision-making. BMC Psychiatry. 2021;21(1):3. https://doi.org/ 10.1186/s12888-020-02928-y.

100. Claassen C, Langdon R, Brüne M. Recognition of social rule violation in "deficit syndrome" schizophrenia: a study using economic games. Front Psych. 2020;11:835. https://doi.org/10. 3389/fpsyt.2020.00835.

101. Patil VA, Jacob AA, Chacko DM, Chakrabarti D, Devi P, Thonse $\mathrm{U}$, et al. Examination of social decision making in patients with schizophrenia using ultimatum game. Asian J Psychiatr. 2020;50: 101937. https://doi.org/10.1016/j.ajp.2020.101937.

102. Lois G, Schneider EE, Kaurin A, Wessa M. Altered neural responses to social fairness in bipolar disorder. Neuroimage Clin. 2020;28: 102487. https://doi.org/10.1016/j.nicl.2020.102487.

103. Bland AR, Roiser JP, Mehta MA, Sahakian BJ, Robbins TW, Elliott R. The impact of COVID-19 social isolation on aspects of emotional and social cognition. Cogn Emot. 2021:1-10. doi:https://doi.org/10.1080/02699931.2021.1892593.

104. Hartley C, Fisher S. Do children with autism spectrum disorder share fairly and reciprocally? J Autism Dev Disord. 2018;48(8):2714-26. https://doi.org/10.1007/ s10803-018-3528-7.

105. Waller R, Wagner N. The Sensitivity to Threat and Affiliative Reward (STAR) model and the development of callous-unemotional traits. Neurosci Biobehav Rev. 2019;107:656-71. https:// doi.org/10.1016/j.neubiorev.2019.10.005.
106. Foulkes L, Neumann CS, Roberts R, McCrory E, Viding E. Social Reward Questionnaire-Adolescent Version and its association with callous-unemotional traits. Royal Society Open Science. 2017;4(4): 160991. https://doi.org/10.1098/rsos.160991.

107. Myerson A. ANHEDONIA. Am J Psychiatry. 1922;79(1):87103. https://doi.org/10.1176/ajp.79.1.87.

108. Husain M, Roiser JP. Neuroscience of apathy and anhedonia: a transdiagnostic approach. Nat Rev Neurosci. 2018;19(8):470-84. https://doi.org/10.1038/s41583-018-0029-9.

109. Calabrese JR, Fava M, Garibaldi G, Grunze H, Krystal AD, Laughren T, et al. Methodological approaches and magnitude of the clinical unmet need associated with amotivation in mood disorders. J Affect Disord. 2014;168:439-51. https://doi.org/10. 1016/j.jad.2014.06.056.

110. Billones RR, Kumar S, Saligan LN. Disentangling fatigue from anhedonia: a scoping review. Transl Psychiatry. 2020;10(1):273. https://doi.org/10.1038/s41398-020-00960-w.

111. Freed RD, Mehra LM, Laor D, Patel M, Alonso CM, KimSchulze $\mathrm{S}$, et al. Anhedonia as a clinical correlate of inflammation in adolescents across psychiatric conditions. World J Biol Psychiatry. 2019;20(9):712-22. https://doi.org/10.1080/15622 975.2018.1482000.

112. Lee $\mathrm{CH}$, Giuliani $\mathrm{F}$. The role of inflammation in depression and fatigue. Front Immunol. 2019;10:1696. https://doi.org/10.3389/ fimmu.2019.01696.

113. Cordeiro LMS, Rabelo PCR, Moraes MM, Teixeira-Coelho F, Coimbra CC, Wanner SP, et al. Physical exercise-induced fatigue: the role of serotonergic and dopaminergic systems. Braz J Med Biol Res. 2017;50(12): e6432. https://doi.org/10.1590/ 1414-431x20176432.

114. Ferentinos P, Kontaxakis VP, Havaki-Kontaxaki BJ, Dikeos D, Papadimitriou GN, Lykouras L. Fatigue in female patients with major depression: the effect of comorbid anxiety disorders. Psychiatriki. 2011;22(4):320-9.

115. Hou T, Zhang R, Song X, Zhang F, Cai W, Liu Y, et al. Selfefficacy and fatigue among non-frontline health care workers during COVID-19 outbreak: a moderated mediation model of posttraumatic stress disorder symptoms and negative coping. PLoS ONE. 2020;15(12): e0243884. https://doi.org/10.1371/ journal.pone.0243884.

116. De Fruyt J, Sabbe B, Demyttenaere K. Anhedonia in depressive disorder: a narrative review. Psychopathology. 2020. https://doi. org/10.1159/000508773.

117. Labouvie-Vief G, Medler M. Affect optimization and affect complexity: modes and styles of regulation in adulthood. Psychol Aging. 2002;17(4):571-88. https://doi.org/10.1037//0882-7974. 17.4.571.

118. Gardner-Sood P, Lally J, Smith S, Atakan Z, Ismail K, Greenwood KE, et al. Cardiovascular risk factors and metabolic syndrome in people with established psychotic illnesses: baseline data from the IMPaCT randomized controlled trial. Psychol Med. 2015;45(12):2619-29. https://doi.org/10.1017/S0033 291715000562.

Publisher's Note Springer Nature remains neutral with regard to jurisdictional claims in published maps and institutional affiliations. 